\section{Developmental continuities and discontinuities $^{\dagger}$}

\author{
RICHARD HARRINGTON
}

The first special section of the Journal on developmental psychopathology (July 2001) provided a glimpse into developmental research on causal processes. This second special section includes papers on two other developmental approaches: the study of continuities and discontinuities over time and the linkages between normal and abnormal development.

\section{DEVELOPMENTAL CONTINUITIES AND PROCESSES}

Longitudinal research designs have been a key feature of a developmental psychopathology research perspective. However, developmental researchers have made surprisingly little use of long-term follow-up studies into adulthood, perhaps because of the practical problems involved in following up large samples of children for 10 years or more. It is therefore pleasing to see here reports from three child to adult followups. Stevenson \& Goodman (2001, this issue) examine data on the adult criminal records of a general population sample of pre-school children who took part in a well-known epidemiological study more than 20 years earlier. They found that certain behavioural problems, particularly activity level, temper tantrums and management difficulties, predicted later adult crime. This finding is consistent with other research on so-called difficult temperament and suggests that in some individuals there is an enduring antisocial propensity that starts very early in life. Similarly, the study of Hofstra et al (2001, this issue) finds significant continuities over time for antisocial behaviour. However, their research also shows that adolescents' self-reported emotional problems, such as depression, predict emotional disorders 10 years later. This result is important because although it used

†See pp. 197-249, this issue. to be thought that adolescent emotional symptoms often were transient, in common with several other studies this research shows that such symptoms can presage serious psychiatric disorders later in life.

It seems then that both antisocial behaviour and depression show significant continuity from childhood into adult life. There is, however, much overlap of these two problems (Angold et al, 1999), raising the question of what happens to young people who have both depression and antisocial behaviour. Are they at greater risk of poor outcomes than children with a single disorder? Fombonne et al (2001a,b, this issue) found that they were. When followed into adult life, child psychiatric patients with the combination of depression and conduct disorder had higher rates of suicidal behaviours, personality disorders and social dysfunction than children with major depression alone.

Conduct disorder overlaps not only with depression but also with attentiondeficit hyperactivity disorder (ADHD). It is important to understand the meaning of this comorbidity for two reasons: its presence is likely to confuse the interpretation of findings on risk factors, because what seem to be risk factors for one disorder may in fact be risk factors for the other; and understanding comorbidity could help us to understand the mechanisms underlying both problems. Using twin study data, Thapar et al (2001, this issue) suggest that the overlap of conduct disorder and ADHD is partly due to shared genetic factors: ADHD that overlaps with conduct disorder could have a greater genetic loading and therefore might be particularly informative for future molecular genetic studies.

\section{CONTINUITIES AND DISCONTINUITIES BETWEEN NORMALITYAND PSYCHOPATHOLOGY}

Although one of the key features of child psychopathology is a focus on a developing person, it is surprising that until recently research on child development and child psychiatric disorders has been largely separate. A further characteristic of the developmental approach is therefore a concern with both the connections and the lack of connections between normality and disorder. The paper by Pickles et al (2001, this issue) shows how for many forms of child psychopathology there is continuity in function between normal development and disorder. Adolescent depression, for example, was just as likely to be associated with impairment below the diagnostic threshold as above it. Impairment was related linearly to symptom count. It should be borne in mind, however, that even when the underlying liability is dimensional, categorical decisions often will be required in clinical practice. There is no case for prescribing small amounts of antidepressant for a little bit of depression!

The topic of continuities and discontinuities concerns not only the distribution of symptoms but also the mechanisms underlying these symptoms. Gowers \& Shore (2001, this issue) show how, at least in some instances, the normal development of weight and shape concerns can follow a developmental pathway that leads to eating disorders. There could be important implications for prevention programmes. Similarly, Goodyer et al (2001, this issue) propose that normal developmental changes in cortisol and other steroid hormones could have a role in the onset and maintenance of some forms of psychopathology in young people. Hormonal changes could help to explain one of the most robust epidemiological findings about depressive disorders, namely that the incidence increases during adolescence.

\section{CONCLUSIONS}

The papers in this and the previous special section (July 2001) provide some excellent illustrations of what can be achieved in developmental research. Because developmental psychopathology has necessarily drawn upon many ideas and perspectives it was not possible to cover all of these in an exhaustive fashion. Conspicuous by their absence are papers dealing with research on the prevention and treatment of psychopathology. Hopefully, however, the two special sections on development and psychopathology will give some idea of the likely future directions for such research. 


\section{DECLARATION OF INTEREST}

None.

\section{REFERENCES}

Angold, A., Costello, E. J. \& Erkanli, A. (1999) Comorbidity. Journal of Child Psychology and Psychiatry, 40, 57-87.

Fombonne, E., Wostear, G., Cooper, V., et al (200la)

The Maudsley long-term follow-up of child and

adolescent depression. I. Psychiatric outcomes in childhood. British Journal of Psychiatry, 179, 210-217.

_, _ _, et al (200lb) The Maudsley long-term follow-up of child and adolescent depression. 2.

Suicidality, criminality and social dysfunction in adulthood. British Journal of Psychiatry, 179, 218-223.

Goodyer, I. M., Park, R. J., Netherton, C. M.,

et al (200I) Possible role of cortisol and

RICHARD HARRINGTON, MD, University Department of Child Psychiatry, Royal Manchester Children's Hospital, Pendlebury, Manchester M27 4HA, UK

(First received 23 April, accepted 9 May 200I)

dehydroepiandrosterone in human development and psychopathology. British Journal of Psychiatry, 179, 243-249.

Gowers, S. \& Shore, A. (200I) Development of weight and shape concerns in the aetiology of eating disorders. British Journal of Psychiatry, 179, 236-242.

Hofstra, M. B., Van der Ende, J. \& Verhulst, F. C. (200I) Adolescents' self-reported problems as predictors of psychopathology in adulthood: 10-year follow-up study. British Journal of Psychiatry, 179 203-209.
Pickles, A., Rowe, R., Simonoff, E., et al (2001) Child psychiatric symptoms and psychological impairment: relationship and prognostic significance. British Journal of Psychiatry, 179, 230-235.

Stevenson, J. \& Goodman, R. (200I) Association between behaviour at age 3 years and adult criminality. British Journal of Psychiatry, 179, 197-202.

Thapar, A., Harrington, R. \& McGuffin, P. (200I) Examining the comorbidity of ADHD-related behaviours and conduct problems using a twin study design. British Journal of Psychiatry, 179, 224-229. 